Massimo Leone*

\title{
Digital Cosmetics
}

\section{A semiotic study on the Chinese and global meanings of the face in image-processing apps}

\begin{abstract}
The earliest extant depictions of the human face are not simply realistic but represented through specific technologies (means) and techniques (styles). In these representations, the face was probably idealized in order to empower its agency through simulacra. The history of art sees humans become increasingly aware of the impact of technology and technique on the production of visual representations of the face. With photography, and even more so with its digital version, technology is developed, hidden, and miniaturized so as to democratize and market technique. The result, however, a naturalization of technology, is increasingly problematic in the era of algorithms: artificial intelligence absorbs the social bias of its engineers. This is particularly evident in the domain of "digital cosmetics": successful apps are used to process and share billions of facial images, yet few critically reflect on the aesthetic ideology underpinning them. This is an urgent task for visual, social, and cultural semiotics.
\end{abstract}

Keywords: digital beautification; racial biases; self-representation; semiotics of the face; social networks

*Corresponding author: Massimo Leone, Department of Philosophy and Educational Sciences, University of Turin, Turin, Italy; Department of Chinese Language and Literature, Shanghai University, Shanghai, China, e-mail: massimo.leone@unito.it

\section{A wish as old as the species: Empowering faces}

Humans have a long-held desire to represent the face. Making one's or others' face(s) present in a distant space or in a distant time through visual simulacra is an old habit of the species. Georges Bataille thought that representations of the face were absent in prehistoric painting (1955), but more and more archeological discoveries seem to indicate the opposite (Aubenas and Biroleau 2003). The earliest known and undisputed figurative human representation, in the caves of the district of Maros in Bantimurung, South Sulawesi, Indonesia, 
dating from 35,400 years ago, depicts a babirusa, a pig-deer (Aubert et al. 2014) (Figure 1). The face is already there, although indistinguishable from the head. Incidentally, disregarding other animals' faces is an old human tradition too.

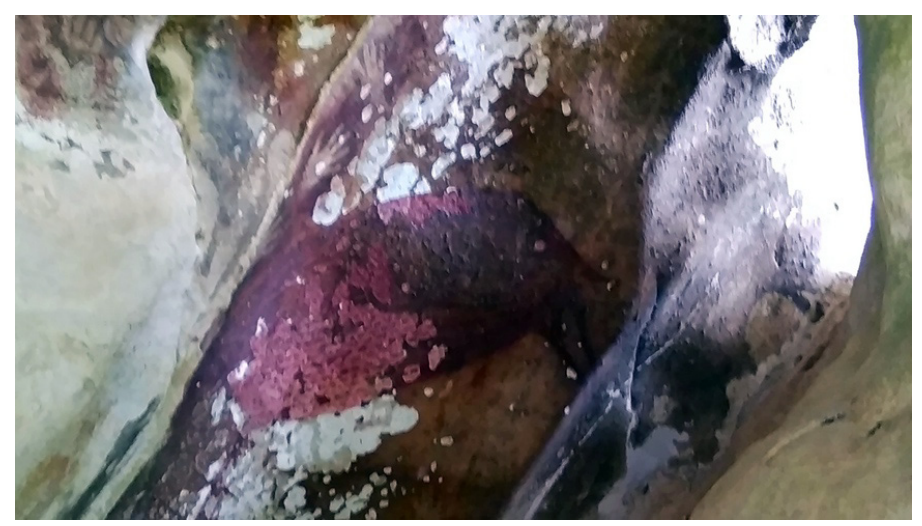

Figure 1: A babirusa depicted in the cave of the district of Maros, Indonesia (image in the public domain)

A cave painting believed to be the earliest known portrait is to be found in Angoulême, France, circa 25,000 BC (Jones 2006) (Figure 2). Sensationalistic articles that call it a portrait, though, ignore the complexity behind the word (Lawson 2012).

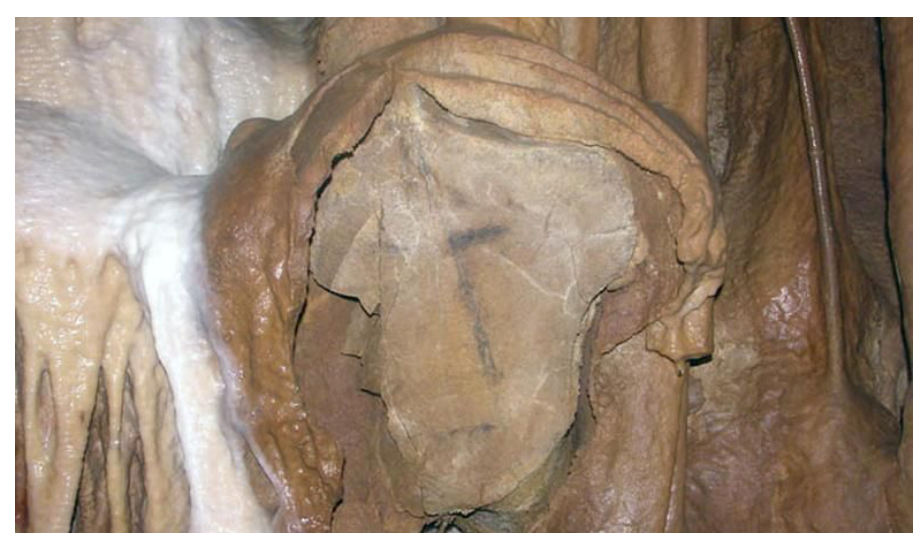

Figure 2: A "portrait" in the cave of Angoulême, France (image in the public domain) 
An independent German scientist, Dr. Michael Rappenglueck, on staff at Munich University, claims that the floor of a cave at La Marche in the Lussacles-Chateaux area of France contains the earliest extant depictions of human faces. They might date from 15,000 years ago. There is no clear correspondence, however, between the cave graffiti and how they are made realistic in reproductions (Figure 3).

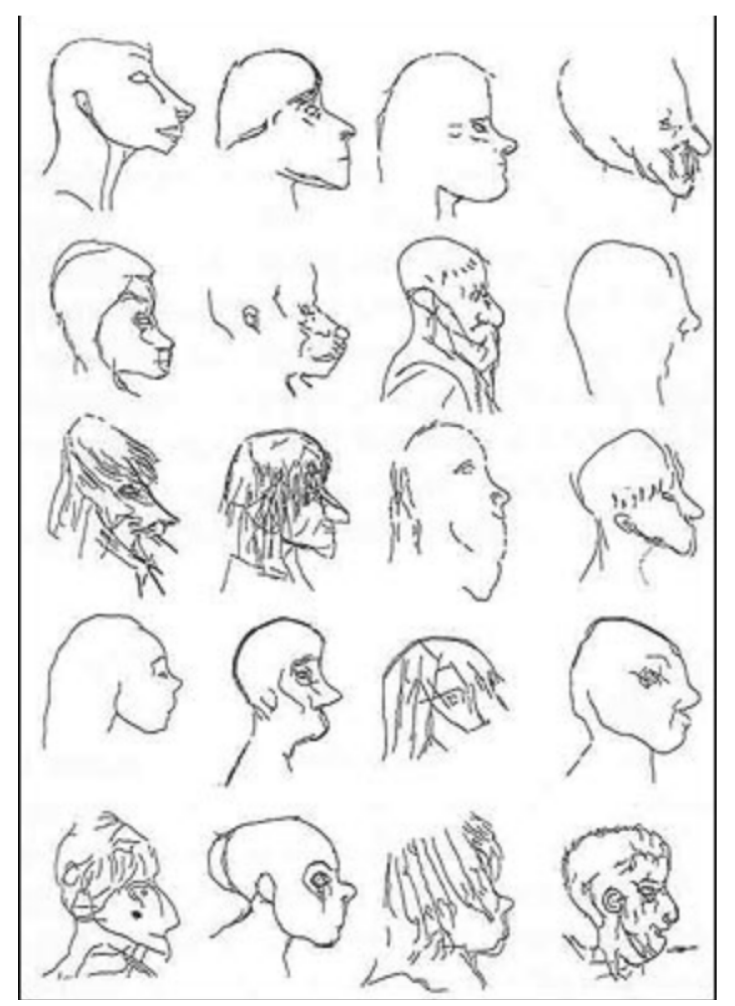

Figure 3: Sketches "reproducing" faces depicted in the cave of La Marche, France (image in the public domain)

A charcoal drawn face is visible in one of the deep, dark chambers of the cave systems on Puerto Rico's now inhabited Mona Island, where humans are thought to have arrived much more recently, between 3,000 and 2,000 BC (Samson et al. 2017) (Figure 4). But is it really a face? 


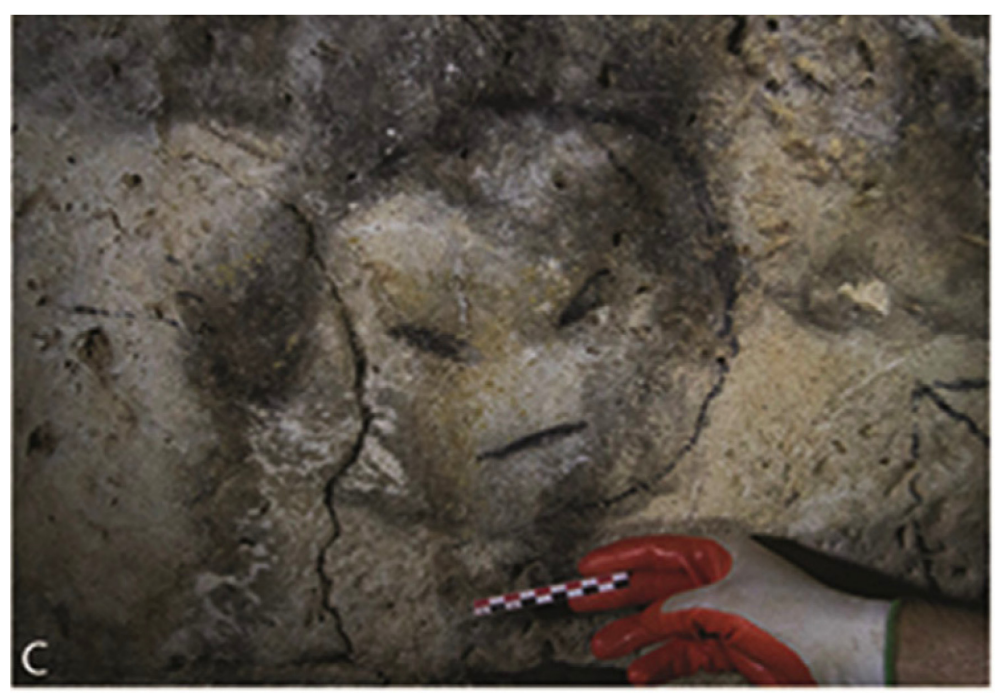

Figure 4: A "face" in the cave of Mona Island,

Puerto Rico (image in the public domain)

These images puzzle. It is not certain whether archeologists see these faces in caves because they were represented therein thousands of years ago, or because these scholars compete against each other for who will find the oldest cave, and the oldest human representation, and the oldest "portrait" (Bednarik 1992). They want to see these faces, and they want these faces to be seen. Is it science, or archeological pareidolia (Bednarik 2016)? In any case, if we take for granted that these actually are human pictures of human faces, it is inevitable to wonder: Were these images supposed to be realistic? Did our progenitors try to depict their faces as they looked? Or were these images, on the contrary, already somewhat idealistic and idealizing, representing faces not as they were seen, but as it was wished they would be seen, bigger, brighter, mysteriously exerting an agency that would somehow empower that of real human faces (David 2017)?

\section{A history of visual awareness}

In such remote times too, images of human faces ended up unrealistic because of the technique and the means of representation. Natural pigments, rocks, charcoal - no wonder the final result distorted the visual idea of a face, 
although grasping its essence. The history of visual representations, "art history" being a part of it, consists in human attempts at becoming aware of the distance between object and image, face and portrait. On the one hand, tools and techniques of representation have become more and more sophisticated: the first paleolithic human who drew a face in a cave was, in a way, a genius, yet this genius could be easily reproduced. Today, anybody could fake the face of Angoulême (including Picasso), but few would be able to fake a portrait by Antonello da Messina. Up to the nineteenth century, indeed, producing a perfectly realistic facial image would require a sophisticated technique, which only few could master. The greatest artists were those who were so aware of the biases of visual representation that they were able to conceal them. Leonardo even challenged the intrinsic steadiness of the painting, making viewers believe that his images were actually moving, like Mona Lisa's smile.

Photography did not only endanger the aura of images, as Walter Benjamin famously claimed. It also made it extremely easy to obtain a realistic image of a face. The difficulty, indeed, was displaced from technique to technology. Especially after the invention of personal and portable cameras, and increasingly so with that of digital cameras, everybody could easily take a picture, although few people would be able to explain the technology behind it, not to speak of manufacturing it. The process was one of inverted proportionality: the technology of paleolithic man was simple, and so was the technique. In the Renaissance, technology was pretty much the same: natural pigments, charcoal, the human body. Yet the technique had progressed enormously: perspective was the achievement of an entire human epoch. With photography, and in general with the advent of the machinic depiction of reality, the situation was completely reversed. Refining the technique became a matter of artistic expression, but the medium itself could be used by a child. Technology became more and more complicated exactly so as to make technique pleonastic: in analogic photography, a photographer was needed in order to reveal the film. The technique was not as complicated as Leonardo's sfumato painting, but it was still for professionals or semi-professionals. With Polaroid, the dark chamber was embedded in the camera. Obtaining realistic depictions of a face depended on a very complex technology requiring a very simple technique, just a click.

The social effects of this progression of technology leading to a regression of technique are evident. On the one hand, realistic representations have been "democratized": anybody, and not only the king's painter, can now come up with a perfectly realistic depiction of a face. Incidentally, this democratizing effect of photography also resulted in bestowing on painting an aura of exclusivity, but increasingly successful attempts are being made in order to 
automatize pictorial depiction too (Yang 2018). On the other hand, less and less technique is required to come up with realistic images, including facial ones, because the technology makes it all automatic. One result is that the "aura" is moved from the artist to the technology maker. Digital photographers struggle to attribute a personal style and an aura to their depictions, whereas Steve Jobs emerges as the new Leonardo of the present time. Yet, Leonardo did not become famous for creating brushes, but for using them. Conversely, Steve Jobs is a guru because he embedded technique into technology, democratized it, and marketed it to the world. He was not an engineer himself, but the one who pushed engineers to squeeze complex human techniques into a tiny, very portable, and very familiar technology.

\section{The essence of an iPhone}

When we purchase an iPhone today, we buy, among other things, the technological promise that we shall be able to disintermediate all those whose knowledge we would have needed, in the past, to produce a realistic image of ourselves or our friends: we do not need a painter anymore, or a photographer, revealing our pictures, for technology gives us the illusion that we are the artists, that we are the photographers, and that we also increasingly are, thanks to the new genre of the selfie, the kings whose portraits the famous artist paints. This promise is so intriguing that it can be sold at a high price to millions of people around the world. It is a promise of autonomous and independent prestige.

This promise comes at a price though. First, although it gives users the illusion of being masters of the technique of representation, it often makes them oblivious to the fact that they completely ignore the technology behind it. We are happy to take beautiful pictures with our phones, but we do not have any clues about how that happens. Second, it tends to "naturalize" the technique: since technology makes it automatic, it also subtracts it to critical consideration. Digital images start to look "natural" to us; moreover, as this article will show, even technologically embedded visual effects, including those that heavily modify facial reproductions, start to acquire an aura of ineluctability. Technique is never questioned because it is a product of technology, but technology is invisible to most. Third, disintermediation through technology inevitably leads to standardization, which is completely at odds with the promise of autonomy that the technological market sells. No artificial intelligence is - up to now at least - as creative as a Renaissance painter. Yet, most users do not realize that the dream of singularity they buy with technology is doomed to be frustrated by 
technology itself. It is the old trick of capitalism: induce people to mistake freedom of choice with freedom of expression.

Contemporary digital technology of representation offers users a large spectrum of choices, yet always within a predetermined range. Leonardo was free in front of his canvas, to an extent that is incomparable to the freedom of digital "photographers" selecting their favorite filters. Most users are given the possibility of choosing among various options, but few users would have the technological ability to create a new option, even less a new app or software, and even less a new phone. What results is a frustrating but still unaware banalization of representation. On the one hand, the market sells a technological promise of aesthetic autonomy. On the other hand, the same promise is frustrated by the inevitable formatting effect of automatization, despite all the efforts to multiply choices and combinatorics so as to conceal the constraining character of technology. One of the most disquieting consequences of unaware standardization is that its biases are naturalized and considered as inevitable byproducts of technology, although its biases clearly have a human origin. We take digital pictures as if they were a personal aesthetic product of an aesthetically impersonal technology, yet we are actually taking pictures with the eyes and the minds of those who created it. The paradox is that they themselves are often ignorant of their own aesthetic biases. A further difference between Leonardo and a present-day Apple engineer is that the former was not only an engineer but also a philosopher. Conversely, it is unlikely that an average Silicon Valley engineer of today, albeit technically brilliant, has any familiarity with Foucault.

\section{The task ahead}

Philosophers and semioticians should neither forgive engineers, thinking that they do not know what they are doing, nor bash on technology, but cooperate with engineers so that digital technology does not absentmindedly absorb the same violent biases artificial intelligence is exposed to when learning from human intelligence. The contribution visual semiotics might give to this process is huge. In the past, semioticians helped uncover the hidden biases of television, advertising, and even apparently innocuous texts like comics. Today, it is fundamental that semiotic analysis turns to technology, not just in order to philosophize on it à la Bruno Latour (which is also important), but also in order to empirically study common everyday technical devices: smartphones, social networks, and especially apps. Currently, the global smartphone owner can 
make use not only of natural pigments, rocks, and charcoal, but also of hundreds of increasingly sophisticated apps. Through them, a wish that is as old as humankind is now satisfied through new means: representing one's and others' face(s); transmitting these images far in time and space; idealizing them so that their agency somehow empowers that of the face itself. Millions of people use these apps day by day, yet they are completely ignorant of the aesthetic and sociopolitical constraints and biases that they, these apps, entail. It is time that semioticians resume their hard work of philosophical contrarians and question this apparently innocent merriment. It is time to critically map the apps, starting from those that are used daily to represent and depict the face.

\section{Geolocalization}

Users of smartphone apps usually forget that they are geolocalized while they are using them, although in most countries they are explicitly asked for the relative permission. They intentionally give away their position in the real world to GPS apps like Google Maps, but also unintentionally provide it in many other cases. There is another kind of geolocalization, however, that users of these apps ignore ever more: they, the apps, did not miraculously emerge from the global web. That is precisely what their global marketing to a larger and larger international audience would like to communicate: we are from nowhere, therefore we are from everywhere, therefore wherever you are, and wherever you are from, and to wherever you belong, we can be sold to you. All marks of geographical and, therefore, sociocultural and sociopolitical origins are eliminated or toned down, not only to attract the global audience and acquire a connotation of young techno-cosmopolitism, but also to downplay any potentially negative local attribute. Indeed, a country of origin might turn into a source of positive branding in some cases, like Italy for food, but negative for others, like Italy for computers (at least since the time of Olivetti). Few smartphone apps developed in China proudly brand themselves as Chinese for the global market, given the reputation of this country as regards the privacy of users. Reputation and reality, however, are not the same: it is indeed quite comic that smartphone users worry about apps developed in China whereas they use those developed in Russia or the USA with no anxiety.

Cultural semiotics, however, should not focus on these geocultural preconditions and implications only. It should also critically appraise those that are ignored by their local users and, even more paradoxically, by the same producers. As smartphone app companies turn global, they become more and 
more anthropologically aware, even contracting or hiring sociologists and other human scientists so as to refine globally and "glocally" their marketing strategies. This anthropological awareness, however, mostly lacks in the beginning, which is nevertheless also when apps acquire their value and specific flavor. An example will clarify the nature of these biases.

\section{Chinese digital beauty}

Meitu is one of the most successful smartphone image processing apps ever, mostly marketed and used in relation to facial images. As the present article is being written, December 2019, Meitu is immensely popular in China and other Asian countries. According to 2016 CNNMoney estimates, in December 2016, it had 456 million users posting an average of more than 6 billion photos every month. Figures have rapidly increased since. As at June 2019, the multiple facial apps of Meitu had been activated on over 1.69 billion unique devices worldwide, with an estimate of 308 million monthly users (MAU) in China, and over 625 million MAU outside of China, with over 10 million users each in Brazil, India, Indonesia, Japan, Malaysia, the Philippines, South Korea, Thailand, the USA, and Vietnam and over 1 million users in 56 countries and regions (estimates provided by Meitu Inc).

The homepage of the Meitu website (accessed December 20, 2019: https://corp.meitu.com/en/about/overview/) reads "What is Meitu?" Above it, a colorful image represents the cartoonish version of a metropolis, its main characters being humanoid cartoons all engrossed in typical Meitu activities: taking selfies and sharing them on social networks (Figure 5).

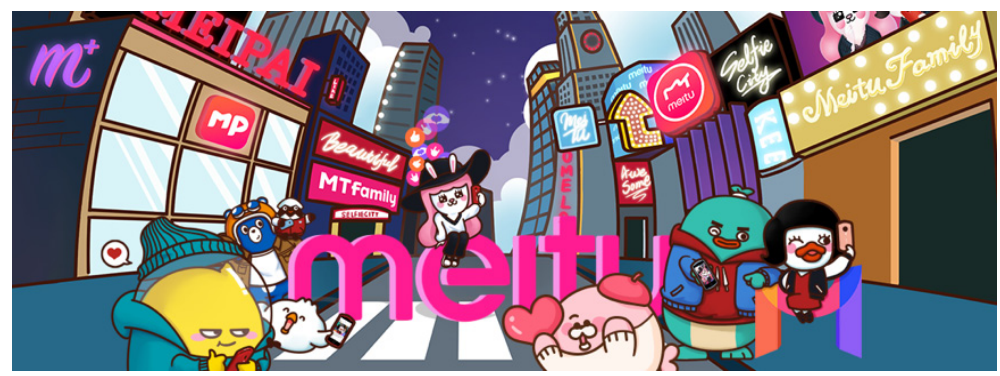

Figure 5: Image on the homepage of Meitu website (image courtesy of Meitu) 
Many aspects would require in-depth semiotic analysis, but one of them stands out: in this cartoonish world, feminine characters take selfies, stretching out their right arm and staring at the screen in the typical pose; masculine characters slyly wink at the girls while pointing at the same selfies as they are being visualized in their - "the guys"” - smartphones. The message is clear: in the cartoonish Meitu world, apps help women take beautifying selfies for the sake of their male partners, who seem to appreciate them. The general atmosphere of the scene is euphoric, as is also the verbal description of Meitu's mission in the same webpage, right under the title: "Founded in October 2008 with a mission 'to make the world a more beautiful place,' Meitu is powered by AI and stands as China's leading imaging and video editing social media platform."

"Making the world a more beautiful place": that deserves deeper analysis, beckoning philosophers and semioticians. First of all, what attracts critical attention here is the confusion between the levels of reality and representation. Meitu apps actually beautify digital images of the world, not the world itself, yet the promise that Meitu makes is not just "to make the pictures of the world more beautiful." Instead, what is implicit in the slogan is either that digital pictures now so prominently figure in the world that the distinction does no longer make sense; or, alternatively, that beautifying pictures of the world will actually make it a more beautiful place. Both are at the core of Meitu's mission. As we shall see, its users are encouraged to leave the digitally beautified world of the app less and less, so that it turns into the main level of their existence and social interaction; at the same time, the company also progressively moves from the industry of "digital cosmetics" to that of real-world makeup, linking the two more and more tightly. On the one hand, Meitu shows how to digitally idealize one's facial image; on the other hand, it indicates how to realign the real face with the digital one. That happens not only through cosmetics but, more and more, through plastic surgery as well (Tolentino 2019).

\section{The evolution of Mei (美)}

Meitu's own description of its mission goes on as follows: "From its earliest days, Meitu has created a series of software and hardware products with the concept of beauty, or Mei (美) in Chinese, at their core.”

Again, the philosopher and the semiotician might want to ask: What kind of beauty? Is Meitu somehow intentionally and unintentionally promoting a typically Chinese idea of beauty; and, if that is the case, what are its 
characteristics, and how do they export into other countries and even continents? Is Meitu, vice versa, importing a typically "Western" idea of beauty, and especially of Western female beauty, into China and secondarily into Asia? In such a case, what are the main traits of this idea? Do they get transformed in the process? Moreover, how do they get re-transformed once they are somehow paradoxically re-marketed outside of China as an expression of Chinese beauty?

There is ample debate among philosophers of aesthetics, in China but also in other countries, about the meaning of the logogram “美” in Chinese (Gao 2018). Used for more than 3,000 years, its etymology is uncertain. Early scholars, maybe under the influence of Confucianist utilitarianism, interpreted it as the merging of two logograms, the one for "large" and the one for "sheep." Early experts of aesthetics in China took it as evidence that the primary sense of the logogram “美” was connected with 'deliciousness,' 'goodness,' and, in general, with the sense of flavor and taste. Later interpretations pointed out that such a hypothesis was perhaps biased by the Confucianist understanding of beauty as naturally stemming from goodness, a bias that was also confirmed when Chinese post-revolutionary scholars sought to extract aesthetic teachings from the writings of Marx and Engels. More recent interpretations resorted to the concept of totem (the large sheep as totemic artefact rather than delicious sheep soup, as was proposed earlier) or, interestingly, to the idea of coiffure: the logogram for "beauty" would actually hint at a body whose head has been adorned with pins: “美."It is a philological fact, moreover, that the earliest extant Chinese literary usages of “美” all directly or indirectly refer to the female body.

A survey of the debate leaves one with the idea that Meitu promotes an idea of beauty that was indeed traditional in remote periods of Chinese culture, but which is not in line with the Confucian idea of beauty, and even less with the utilitarian idea of it promoted by Chinese Marx interpreters. Whereas for Confucius beauty was inseparable from goodness, and whereas for Chinese Marx exegetes it is inseparable from usefulness, Meitu promotes an idea of beauty as exterior adornment, essentially confined to the valorization of the female body (Quan 2019). Nevertheless, such a conclusion should be nuanced: Meitu in China is being increasingly used not only for the purposes of visual seduction but also in the job market (Xu and Feiner 2007): Chinese girls are choosing Meitu more and more to beautify their profile pictures in digital and on paper CVs. The power of semiotic analysis, however, is that it does not stop at words. It does not stop at pictures either. We can delve into the app and analyze what it allows users to do with images of their faces, and what kind of beauty it offers to them. 


\section{The semiotics of Meitu}

Let's analyze first one of the most popular Meitu products so far, the main Meitu image processing app, iPhone 8.7.11 version, available for free in the Apple store. The logo of the company also becomes the icon of the app but, significantly, the Chinese logograms are gone. That cannot be justified only because I downloaded an international English version of it. It is also a way to "deChinesize" the app, to globalize it without any direct reference to China. When I open the app, six rectangles in pastel colors appear on the screen; from topright to bottom-left: "Edit," "Beautify," "Video," "Collage," "Meitu AI," and "Tips." "Extra functions" and "Preferences" are available from two little icons in the top-right corner of the screen, whereas the logo of Meitu appears in the top center of the screen and the icon of the camera in the bottom center. It is worth noting that the rectangle of the function "Beautify" is dark pink and contains a little icon in the top-right corner, representing a sketchy female face with long hair and eyelashes as the only visible parts, white on pink. A little star appears on the small head (Figure 6). Although most users of Meitu might not realize it, the app is entirely built on having as its "ideal" user a young female person, which is the person whose face the app is there to beautify. The same sketchy icon of a female head, although with longer hair and a different haircut, also appears in connection with the function "Meitu AI": all the artificial intelligence efforts of the app go in the direction of beautifying the female countenance.

Let us press the button "Beautify." As is usual in apps of this kind, we are asked what the desired source of the images to be processed is, either the gallery or the camera. Incidentally, that is when privacy issues arise, given that Meitu and similar apps have access to pictures stored on one's smartphone. Let us leave this question to law and ethics specialists, however, and continue with the cultural semiotic analysis. Here too, though, privacy issues are relevant, but in the sense that users often neglect them exactly because they are too engrossed in the mission of beautifying their facial images. In order to avoid privacy issues, especially considering the very stringent European legislation on face research (GDPR, etc.), in this paper I shall be working with my own face, and with a picture of it I took with an iPhone 7 in 2018, precisely during one of my stays as visiting professor at Shanghai University (Figure 7). 


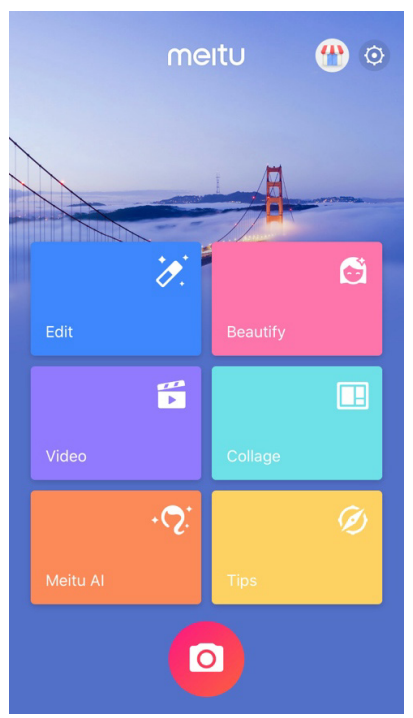

Figure 6: The main menu of Meitu (image courtesy of Meitu)

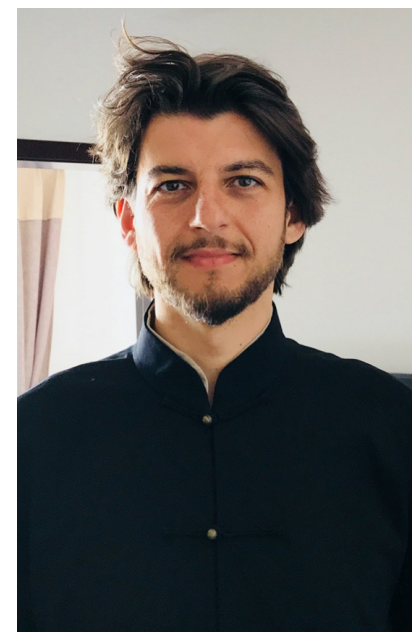

Figure 7: A picture of myself taken with an iPhone 7 in 2018

The choice, however, is not neutral. First, although no filters were used to take it, it nevertheless results from a specific technology (the camera of an iPhone 7), a specific setting (the sparely furnished sitting room of my Shanghai apartment), specific conditions of light (a luminous early spring morning), and, above all, a specific body (mine in 2018). This body is indeed the biggest 
problem, since it is most probably not at all the body of an "ideal user" of Meitu. Meitu, as we shall see, is mostly designed for young Chinese and Asian girls, not for an adult Caucasian male (no matter how Chinese his clothes might look). In any case, testing how the app reacts to this "non-ideal user body" is also relevant, given the more and more globalized scope of the app's audience.

What can I do with my face on Meitu? Or, put differently, what does Meitu expect me to do with my face? Remarkably, on the main screen of the app, the two functions "Edit" and "Beautify" appear as separate. "Editing" regards the picture as a whole, while "Beautify" specifically aims at the human body and particularly at the face. Meitu indeed markets itself as an app to better the appearance of pictures, but with the implication that these pictures mainly represent the face, and actually the young female face. Once I have chosen my picture, Meitu proposes the following functions: "Makeup," "Auto," "Smooth," "Skin," "Reshape," "Slim," "Acne," "Contour," "Firm," "Body Shape," "Enlarge,” "Dark-Circle,” and "Brighten” (Figure 8):

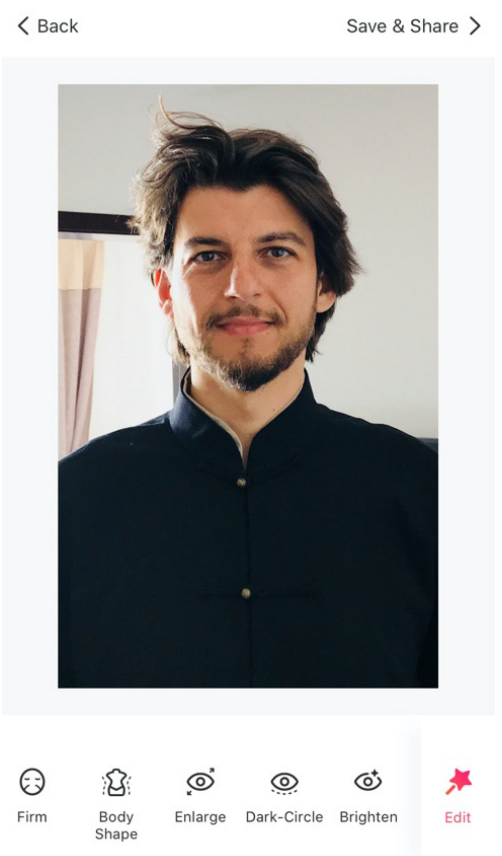

Figure 8: The options of the function "Beautify" in Meitu 
At any moment, the user is given the option to switch to the "Edit" function, go back to the main menu, or go to the function "Save and Share." The options of the function "Beautify" are interesting for two aspects in particular: the icons they are associated with and the aesthetic axiology that their names reveal. As regards the former, many of them explicitly refer to the female body or face, either through referring to typical feminine makeup tools (e.g., the lipstick for the function "Makeup" and the brush for "Contour") or to a sketchy female head (like the face with longish hair of the option "Auto" or the female silhouette of "Body Shape"). Interestingly, axiologically neutral options appear side by side with the connoted ones: the subfunctions "Skin," "Reshape," and "Body shape" do not contain any axiology, whereas "Smooth," "Slim," and "Firm" do; juxtaposing them all, Meitu implicitly naturalizes the idea of a "smooth," "slim," and "firm" body/face. Moreover, the stigmatization of their opposites, an "unsmooth," "plump," and "soft" body/face is emphasized by the straightforward occurrence of a dermatological disease, "Acne," among the subfunctions. It is, of course, a nod toward the "ideal user" of the app, a teenager, but is also a way to pathologize unwanted aesthetic looks.

\subsection{Digital hegemonies 1: Enlarging eyes.}

The icons devoted to subfunctions concerning the eyes deserve special attention. "Enlarge," in particular, seems to suggest that having small eyes is comparable to having a plump body, which is comparable, in turn, to having acne. The app, therefore, implicitly pathologizes not only aesthetic conditions (like being plump versus being slim), but also somatic conditions. For Meitu, having large and bright eyes with no dark circles underneath is an aesthetic value. It is difficult, however, not to see any ethnic connotations in this implicit axiology. Is perhaps Meitu, which purports to treasure a Chinese sense of beauty, hijacking the ethno-political hegemony of Western eyes, marketing them in the new domain of "digital cosmetic surgery"? What can Meitu do with my own eyes, for instance?

If I choose the function "Enlarge" [the eyes], the app gives me two options, "Manual" and "Automatic." That is interesting, because if I must process one image only, I shall probably go manual, but since I shall probably end up processing a myriad of images of my face over time, eventually, for most of them, I shall probably opt for the faster “Auto.” Most users will not wonder, however, who decides how large my eyes should be in order to be automatically beautified. A quick answer might be: the algorithm! This answer is given more and more, not always neutrally. Some scholars fear the pernicious influence 
that algorithms might have in our life. The fear increases when artificial intelligence comes in. This attitude, however, somehow contributes to turning algorithms into neutral and impersonal agents. It is true that some of their results might not have been planned by their human creators. This is becoming increasingly true as algorithms complexify. Yet, one should not forget that artificial intelligence is never completely artificial. It must be trained by human trainers. AI algorithms then often end up absorbing the biases of all those humans that, responsible for some stage of their production, must choose among different options. They must, for instance, choose the pictures that face AI apps are "fed" in order to be trained. So, what is the bias of Meitu as regards eyes? If I choose the automatic option, the app by default sets the processing at an average intensity. That is interesting too: who decides what are the extremes of the spectrum? Opting for minimum intensity, my eyes in the picture do not change at all. If I opt for maximum intensity, instead, the final result is the following (Figure 9):

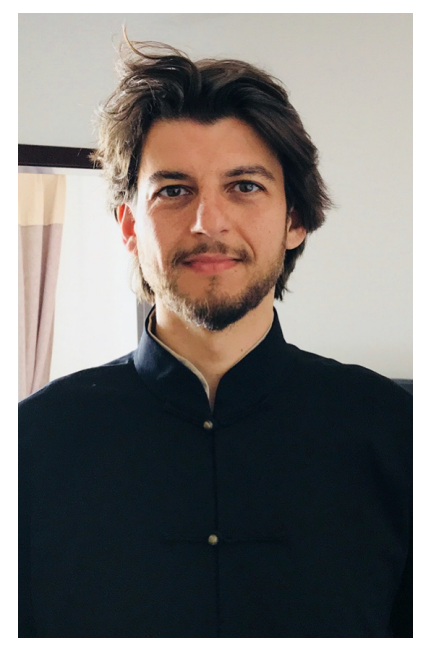

Figure 9: The digital picture of my face with eyes enlarged by Meitu

The effect is more visible if the initial picture is compared with the final one (Figure 10): 

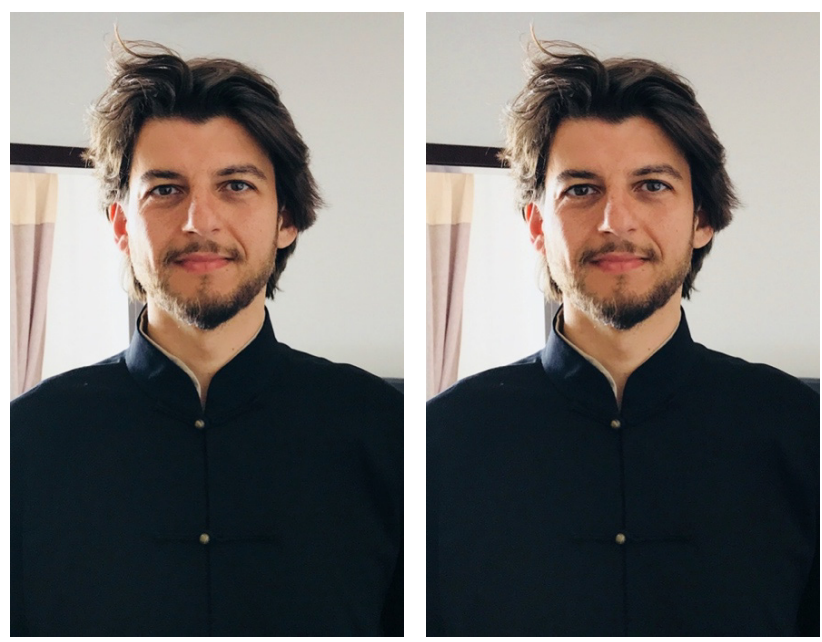

Figure 10: The digital picture of my face, compared with the processed version of it (enlarged eyes)

Yet, one should keep in mind that the "ideal reader" of the second image is usually not able to compare. In some cases, he or she (most likely, he) will have seen the actual face of the picture or previous photographs of it. In many other cases, however, for instance for people browsing the profile pictures of Tam Tam - the popular mostly Chinese dating social network - the first impression of the person will depend on the "beautified" picture. As a consequence, the app must somehow be "moderate," meaning that its purpose is not so much to change faces for fun, like Snapchat or other similar facial apps, but to "beautify" them in a realistic way. People who receive my picture with enlarged eyes must therefore believe that a face like mine is actually possible in nature, not that it is a monstrous one.

The app exploits, on the one hand, a biological feature: bigger and brighter pupils are often a sign of increased attention and sexual excitement. Staging my identity through the beautified picture above, I construct my ideal reader as one whose presence in front of me will literally make my eyes open and excited. A picture with my enlarged eyes will therefore probably attract the gaze of the potential viewer, but the effect should not be exaggerated: above a certain limit, they will look bulgy and bulky, triggering puzzlement more than excitement. On the other hand, though, the app also exploits a cultural bias: in most of East Asia, girls will have interiorized the hegemonic seductive power of Western eyes. Resulting from a long-period geopolitical disequilibrium between the East and the West, they become its expression in the beauty market, turn into aesthetic 
capital, and are sold to young Asian teenagers so that their staged identity might conform with the fantasies of the mainstream male audience.

This transformation, however, is not without consequences. The cultural effects are evident: the hegemonic stereotype of Western eyes being more attractive than Eastern ones is confirmed and strengthened. Other secondary aesthetic effects are less evident: in order to "enlarge" the eyes, the app tends to standardize their shape, erasing some of their singularity. That is probably a general bias of AI beautifying algorithms: so as to make the face more in line with ideal beauty standards, it tunes down its singularity. Beautified faces, therefore, all tend to show a disquieting resemblance, exactly as in plastic surgery. "Meitu faces" become predictable and recognizable like Instagram meals or Facebook landscapes, for the algorithm makes them more attractive in one way, but also duller in another.

\subsection{Digital hegemonies 2: Smoothening ethnicity}

Let us now test another function of the app, "Smooth," always with the highest intensity allowed by the algorithm (Figure 11):
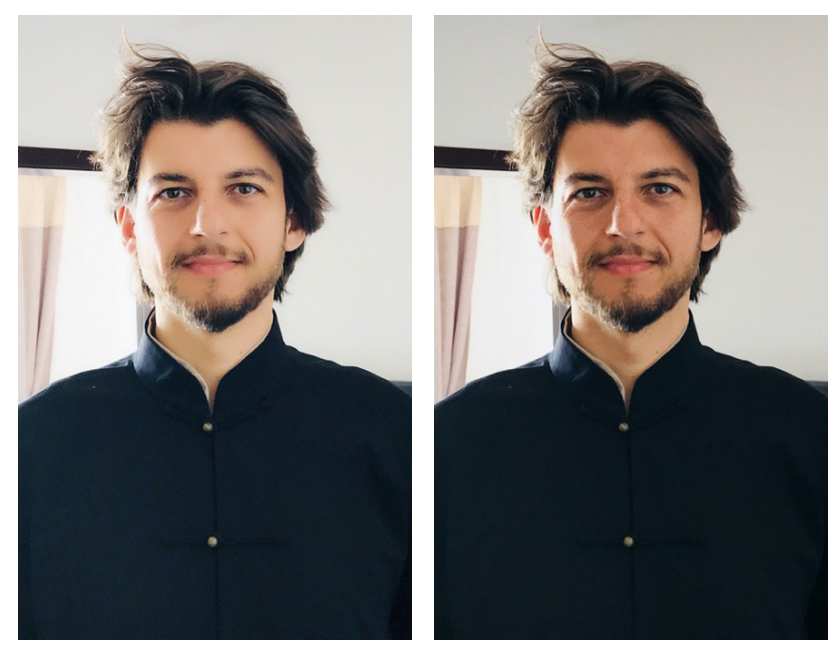

Figure 11: The digital picture of my face, compared with the processed version of it ("smoothened" skin)

Comparing the beautified image with that of departure, the critical viewer must reach the conclusion that "smooth" is just a cover word for "whiten." If I 
ask the app to "smooth" my face, it will actually make it look whiter. That attributes to my face many of the connotations that centuries of Caucasian sociopolitical hegemony have diffused throughout the planet. The average Chinese teenager might uncritically use this function, yet it is no exaggeration that it represents, under the form of an app, the whole history of global pigmentocracy: white is more attractive, it is purer, it is younger. All this becomes politically correct under the label of "smooth." But "smoothening" something actually means removing the imperfections, the obstacles, the impurities, what is extra and unwanted. What Meitu smoothens out of my face, hence, is the darkness of my Italian skin, the marks of my forties on my face, but also a whole bunch of negative connotations that brown skin has had around the world for centuries.

\subsection{Digital hegemonies 3: Cleansing race}

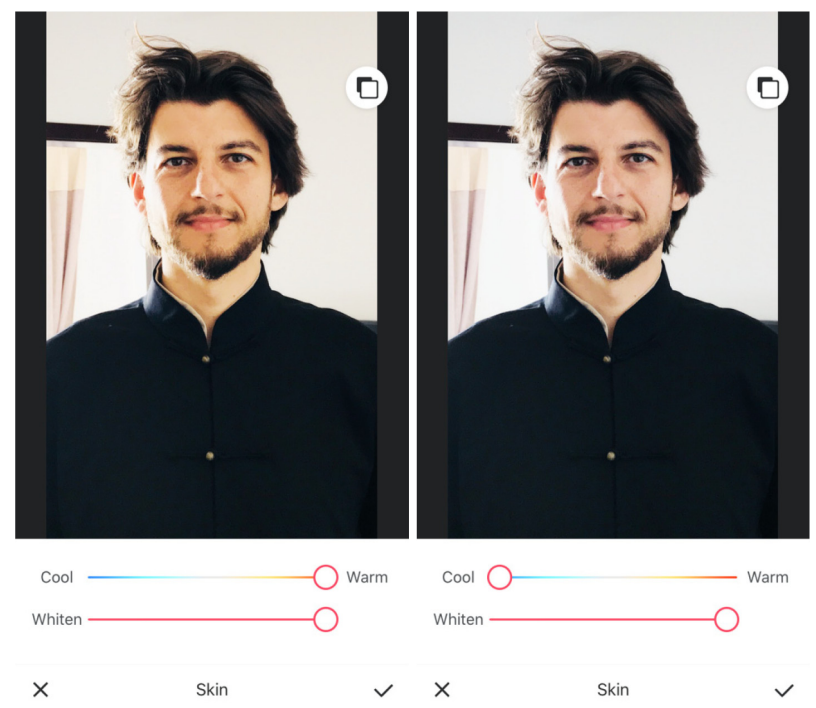

Figure 12: The digital picture of my face, in the "Warm/Whitened" or "Cool/Whitened" version

The bias is even more explicit in the function "Skin," which has two options, each with a predetermined spectrum: the first is between "Cool" and "Warm," whereas the second denominates only one polarity: "Whiten." The app 
therefore pushes me to be a warm white or a cool white, which are both acceptable as long as I stay white.

\subsection{Digital hegemonies 4: Filtering naturalness}

The same pigmentocratic imbalance is also at work in the function "Auto": if pressed, it immediately whitens my face and offers a series of prearranged patterns for automatic beautification. Each has a name and is exemplified through the face of an Asian female model in different versions. In the English version of the app, the options are the following: "Natural," "Fancy," "Airy," "Fresh," "Sweet," “Eastern," "Youthful Look," “Caramel Look,” “Classy,” and "Hushed." These denominations themselves deserve critical attention. Indeed, they are not at all part of the same semantic field. Some of them refer to age, like "Youthful Look," some to social class, like "Classy," some to sensorial appearance, like “Airy," "Fresh," and "Caramel Look," and one is geo-ethnic: "Eastern." It is worth underlining that the subfunction "Natural," which is activated by default when the function "Auto" is chosen, does not give as a result the unmodified picture. The "zero degree" of Beauty for Meitu indeed is not the picture of the face as it is, but the picture with a more favorable light, which makes one's face look younger and whiter (Figure 13):

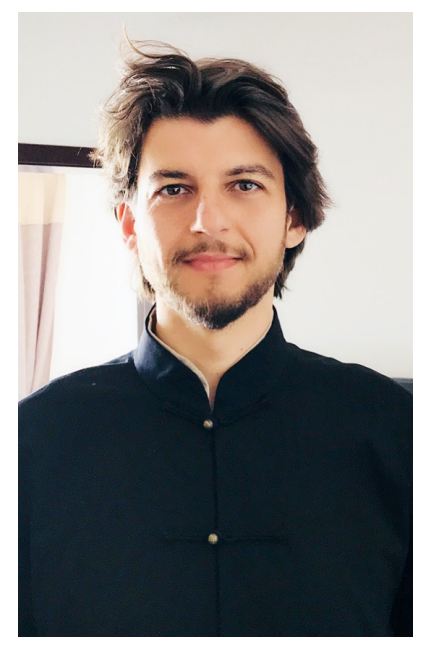

Figure 13: The digital picture of my face, in the "Natural" Meitu version 
That is relevant especially as it implicitly gives users the idea that the pictures that they "spontaneously" take with their cameras are intrinsically defective. They must be processed by Meitu before they are shared through social networks. Meitu promises to beautify the world, but its main app cannot do it directly: it must rely on digital pictures that people take. Hence, users must be convinced that, even if they want to look "natural," their pictures must be made "beautifully natural" by Meitu. Photographs before Meitu are intrinsically connoted as wanting, and Meitu as their antidote. That is why Meitu users are likely to develop an addiction to the app. Without it, they will not consider their pictures as sharable. Moreover, Meitu has started to develop its own smartphones. Indeed, for Meitu, smartphones are not a device for communication. They are not meant to be used as cameras either. They must be conceived first and foremost as devices for taking selfies. The latest-designed model (2019) has three objectives on a back camera (Figure 14), which can also rotate to become a front camera. In its default position, however, the "eyes" of this smartphone are oriented toward the user, and not toward the world. The "ideal usage" of this smartphone indeed consists in taking selfies, not in picturing the world.

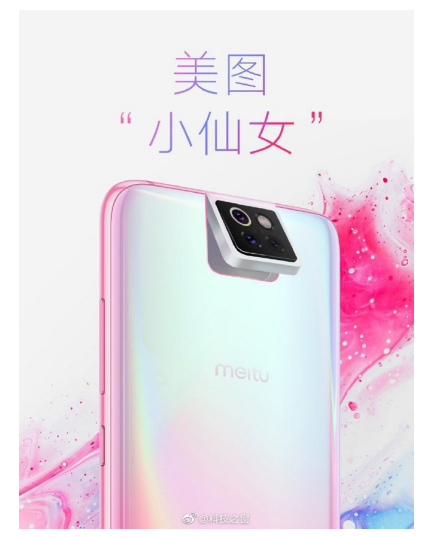

Figure 14: the latest model of Meitu smartphones (image courtesy of Meitu)

\section{The face as brand}

The selfie-centric nature of Meitu is, indeed, explicit: although the slogan of the company mentions a world to be beautified, this world actually has a face, and is the face of the user, his or rather her selfie. Slogans that Meitu chooses for its 
global audience are, from this regard, quite telling. One comes across the first of them on the homepage of the Meitu website: "Your Photos. Your Brand. Your Story." The foreground of the page contains the vivid picture of a smartphone showing the lively picture of a young woman smiling from the processing page of the app (Figure 15). The woman's countenance is ethnically multiple: she has perfectly white teeth, an open smile, Caucasian complexion and red hair, yet her eyes, although clear, have an East Asian touch. That might appeal to an ideal user of Asian ethnicity wishing to "Westernize" her face, but also to a complementary ideal user from the Caucasian West wanting to "Orientalize" her look: the ethno-cultural and somatic global hegemony is, indeed, changing the epicanthic fold is becoming increasingly popular in the global beauty market.

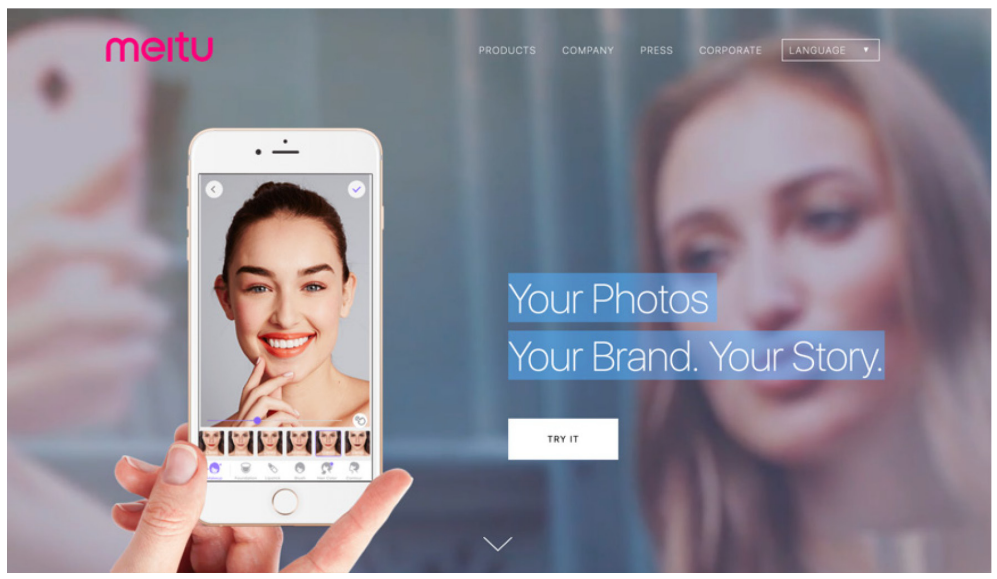

Figure 15: One of the main pages of the Meitu website (image courtesy of Meitu)

The background of the webpage is even more interesting: there appears the slow-motion video of a girl who is taking a selfie. The video is blurred though, and the features of the girl cannot be recognized easily. The relation between the foreground and the background is telling: Meitu is a "magic helper," as narrative theory calls it. It allows the blurry, undefined, and gloomy representation of a body to turn into the shiny, perfectly defined, and glorious picture of a face. The slogan interacts with this combination of foreground and background, "before" and "after" Meitu; its syntax underlines the identity of the user - "Your" photos, "Your" brand, "Your" story - but, above all, it suggests that each individual is called to create their own brand in the world. Not a personality, then, but a brand. A typical commercial concept is translated from 
marketing to interpersonal relations. The result is clear: the main difference between "personality" and "brand" is that the latter is the object of a commercial transaction; it is sold and bought. Meitu intentionally or unintentionally circulates in both the Chinese and the global culture the idea that the face is aesthetic capital that one sells and buys, not only in the domain of seduction but also in any other field of human activity. The face is not a logo, since its appearance is doomed to change all the time and must also change all the time to adapt itself to context. Yet, a brand can be imprinted on the face so that it is always recognizable, not as mere face but as the expression of an individual's worth in the global market of aesthetic capital. The slogan mentions "Your Story." Indeed, "storytelling" is also a magic word in the marketing of the face: it is not sufficient, Meitu seems to suggest, that we process one of our facial pictures, since our face can be turned into the living, biological support of a brand only if it is coherently "narrated" throughout, picture after picture, video after video. Meitu offers itself as the indispensable tool of such narrative branding.

\section{Semantic, syntactic, and pragmatic punctum}

Other slogans of the company confirm this message. "Make every photo worth sharing," for instance, suggests that photos are not intrinsically worthy of communication (Figure 16). Using Meitu is indispensable so as to turn a banal picture into one that is worth sharing. This slogan also has a second implication: Not every picture is worthy of sharing (first message), but Meitu makes it so. That deserves further semiotic reflection.

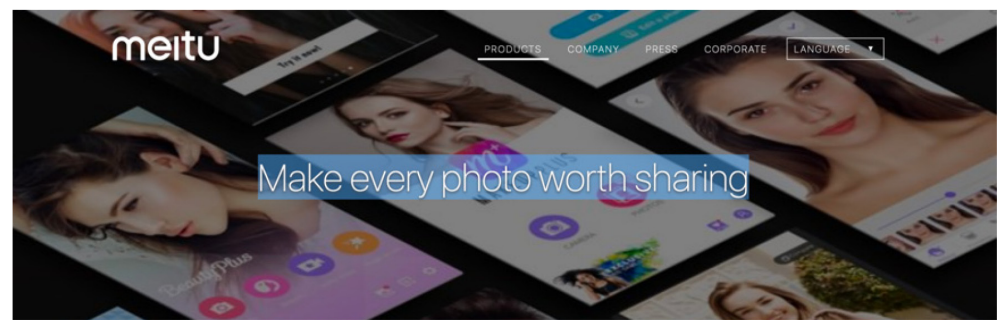

Figure 16: Another page of the Meitu website (image courtesy of Meitu)

How does Meitu turn a banal picture into a sharable one? It cannot work on the content of photographs, although it is able to detect faces in them. Even in the 
case of faces, though, artificial intelligence provided by Meitu disregards the actual semantics of the picture and focuses exclusively on its syntax and pragmatics. The issue is actually more complicated. If I choose the option "Auto" from the function "Edit," Meitu recognizes that my picture contains a face and automatically proposes that I adopt the correspondent processing pattern. Other patterns are named "Food," “Objects," "Scenery," "Defog” (which is an inappropriate categorization, since it is an operation and not a content), "Person," and "Pet." Meitu lists the most common categories of objects photographed by people, but also encourages them to recategorize what they photograph in keeping with this list. On the one hand, there is no specific pattern for "people." "Objects" are named in the plural but, interestingly, "Person" is rather preconceived as individual. Incidentally, the individualistic approach of Meitu (which is not characteristically "Asian" and "Chinese", but rather Wasp) shows also when the app is used to beautify a group picture: the user is asked which faces are to be beautified therein. It is indeed possible to beautify one's face in a group picture while leaving all the other faces "unbeautified." Other biases are conveyed by this categorization and by the association of labels and icons. For instance, "Objects” are represented by a flower, there is no mention of artworks, "Person" is, again, represented by a feminine icon, and "Pet" by a dog (are cats already so beautiful that they do not need any digital beautification?).

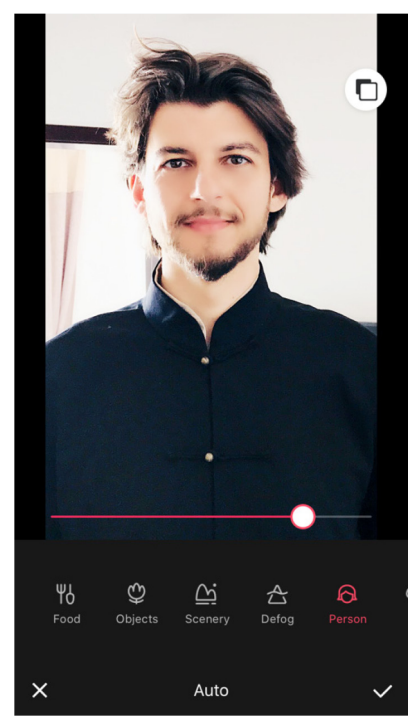

Figure 17: My face "beautified" according to the pattern "Person" 
Yet, the deepest biases are, as usual, visual. Meitu implicitly suggests that there is a single way to automatically beautify each category of object. The picture of my face beautified according to the category "Person" gets whitened, rejuvenated, thinned, and exposed to a brighter and more favorable light (Figure 17).

But what if I offer myself to a "cannibal look" and choose the option "Food" instead? Here is the result (Figure 18):

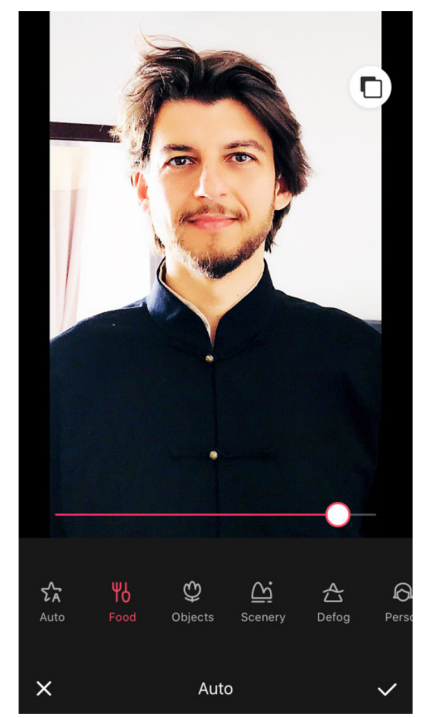

Figure 18: My face "beautified" according to the pattern "Food."

Immediately the light becomes golden and warmer, my face thicker and rounder, the color of my skin is stripped of the angelic diaphanousness that it emanated under the previous pattern and is given the plump, golden hue of baked goods instead. It is as though, in the visual ideology of Meitu, faces were mostly meant to be admired in a sort of mystical aura while food was meant to be fleshy, touched, and devoured with the eyes. Other visual biases are implicit in the other patterns, but one is common to them all: for Meitu, there is one ideal way to beautify each category of objects, and this way has nothing to do with the specific object to be beautified. Artificial intelligence, indeed, cannot enhance the semantic "punctum" of the picture, as Roland Barthes would have called it, but rather its syntactic and pragmatic studium. The picture of a face beautified through Meitu might indeed look appealing to most, since the AI algorithm behind the beautification is perfectly in line with the global aesthetic 
Zeitgeist. Yet, in this case too, what is lost is specificity. A picture does not attract anymore because of its singular content and form, but because of the patina superimposed on it. If it is true that beautiful pictures all look alike while ugly pictures are all ugly in a singular way, then that is even more true as regards digital processing: Meitu faces are all attractive, but they are all attractive in the same way. From this point of view, another app by the same company, AirBrush, deserves commentary. Its description reads as follows: "Designed for both men and women, AirBrush gives smartphones users professional-grade photo retouch with achieve [sic: probably read "which achieves a"] natural look with undetectable edits. Manually eliminate imperfections and applying [sic] flattering filters perfect for social media and professional headshots."

The underpinning ideology is evident: if you use Meitu's free products, you can edit and beautify your face, but people will probably realize this. They will realize that you have used a filter, for instance. No matter how sophisticated and beautifying filters are, they nonetheless remain filters. They manifest themselves only through the pictures they modify and, hence, do not have intrinsic value. Moreover, no matter how much they are appreciated, everybody would prefer them to work exactly like cosmetic surgery: enhancing, effective, but invisible. Yet, here a differentiation is in order. Some facial digital processing works like makeup: it must be visible to a certain extent in order to be appreciated. Viewers will be more or less capable of detecting its presence, but it is not supposed to pass completely undetected. Makeup is, by definition, something that is perceptible. In the domain of makeup too, though, one should distinguish between enhancing makeup and correcting makeup: a girl might want to show the lipstick on her lips, for it enhances their fleshiness, but the same girl would certainly not want the brush she uses to dissimulate her pimples to manifest itself as a cover-up. The same goes for digital makeup: it is generally $\mathrm{OK}$ if we use a filter to beautify the afternoon light of a marine scene, but it would be an aesthetic social mistake to simulate sunlight in a picture in such a clumsy way that viewers actually think that we are lying.

Greimas' square of veridiction can help systematize these nuances. No picture tells the ontological truth about reality, since a representation is not a replica and an ontological replica is probably even impossible, as Umberto Eco already intuited, following Borges (Eco 1982). Thus, what is at stake here is veridiction, not truth. Let us posit the case of the unmodified picture posted in a social network. As regards veridiction, viewers' reactions can be ranged along a spectrum, going from "this is a beautiful, authentic picture" to "this picture looks beautiful because of the filter." In the first case a "truthful” photograph is received as such; in the second, it is received as a lie. But let us consider the 
opposite case of a beautified image: in the first case, it is received as a photograph that "can keep its secret," whereas in the second one, it is also considered as a lie. More generally, we want digital processing to enhance those aspects of reality that we like, and we do not particularly care whether the processing is visible or not, as long as the final result is attractive (exactly as with makeup). But we also use digital processing to conceal those aspects of reality that we dislike, and in such case, we absolutely want the processing to be effective but secret, otherwise it would be a boomerang, underlining exactly those faults that we want to hide. There are, then, ironic effects of digital processing that are exactly like intentionally kitsch makeup: they voluntarily disclose the processing by exaggerating its usage, also in order to magnify unwanted aspects of reality. An interesting characteristic of Meitu is that it is generally not possible to use it ironically or parodically, for the app intrinsically limits the spectrum of processing to realistic effects. One cannot whiten one's face in Meitu so that it becomes unbelievably diaphanous, for instance.

\section{Conclusions: Standards of veridiction}

All these considerations should also take into account that the standards by which we judge the veracity of pictures are also constantly changing with technology and the consequent evolution of social taste. As Meitu filters are increasingly adopted to beautify pictures, they turn into "aesthetic habits." Hence, they are less and less perceived by viewers and they are actually missed only when they are not there. The unfiltered facial image becomes a little like unsophisticated wine (like some bio wines): it might be purchased by some out of a snobbish quest for authenticity, yet in the end most will consider it to be less pleasant than properly sophisticated wine. These digital aesthetic habits, though, end up neutral: since they set the standard, to the point that not using them is connoted as ugly, they also lose their added value. More and new filters will have to be invented and adopted so as to make a picture stand out in relation to the average. Some will try to distinguish themselves by rejecting filters, some others will resort to beauty patterns from the past. For instance, Meitu filter V21, in the "Movie" series of filters, can give my facial picture the quaint aesthetic of an old photograph, even simulating overexposure, that is, a "mistake" that would be impossible in the digital world (Figure 19). 


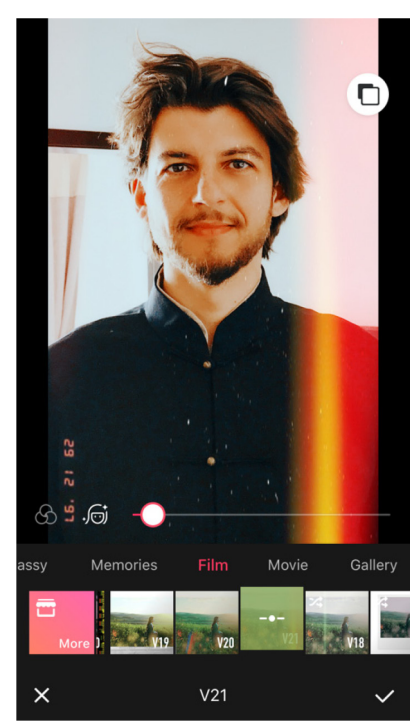

Figure 19: The picture of my face processed with a vintage movie filter.

In the end, though, snobby rejection of all filters or nostalgic adoption of antiquing filters can work only parasitically, in contrast with the average standard. Aesthetic and social distinction in representing and presenting one's face is ultimately possible only through positive strategies. The face can regain a photographic aura either through artistic invention (the content, the semantics of the facial image) - seeking a punctum (in the sense of Barthes 1980) that is more and more difficult to reach in the conundrum of contemporary art - or through technological invention (the expression, the stadium, the syntax and pragmatics of the facial image), whose products are bought and sold in the market as assets of aesthetic and social capital.

Funding: This publication is part of a project that has received funding from the European Research Council (ERC) under the European Union's Horizon 2020 research and innovation program (grant agreement No 819649 -FACETS).

Acknowledgements: I thank PIAST, the Polish Institute of Advanced Studies in Warsaw, Poland, for granting me quality time to complete the writing of the present article. 


\section{References}

Aubenas, Sylvie \& Anne Biroleau (eds.). 2003. Portraits/Visages. Paris: BnF/Gallimard.

Aubert, Maxime et al. 2014. Pleistocene cave art from Sulawesi, Indonesia. Nature 514. 223227.

Barthes, Roland. 1980. La chambre Claire (Cahiers du Cinéma - Gallimard series). Paris: Gallimard.

Bataille, Georges. 1955. Lascaux, ou, La naissance de l'art : La peinture préhistorique. Geneva: Skira.

Bednarik, Robert G. 1992. Palaeoart and archaeological myths. Cambridge Archaeological Journal 2(1). 27-43.

Bednarik, Robert G. 2016. Rock art and pareidolia. Rock Art Research 33(2). 167-181.

David, Bruno. 2017. Cave art. London: Thames \& Hudson.

Eco, Umberto. 1982. La mappa dell'impero uno a uno. Alfabeta 38-39. 3; republished as Umberto Eco. 1992. Dell'impossibilità di costruire la carta dell'impero 1 a 1. In Umberto Eco, Il secondo diario minimo, 157-163. Milan: Bompiani.

Gao, Jianping. 2018. Aesthetics and art (China Academic Library). Berlin \& Heidelberg: Springer.

Gary Xu \& Susan Feiner. 2007. Meinü Jingji/China's beauty economy: Buying looks, shifting value, and changing place. Feminist Economics 13(3-4). 307-323.

Jones, Jonathan. 2006. Old masters. The Guardian, June 6. https://www.theguardian.com/artanddesign/2006/jun/06/art (accessed 30 December 2019).

Lawson, Andrew J. 2012. Painted caves: Palaeolithic rock art in Western Europe. Oxford, UK: Oxford University Press.

Lwoff, Stéphane. 1942. Fouilles Péricard et Lwoff à La Marche (Vienne) - Industrie de l'Os. Bulletin de la Société préhistorique française 39(1-2). 51-64.

Péricard, Léon \& Stéphane Lwoff. 1940. La Marche, commune de Lussac-les-Châteaux (Vienne): Premier atelier de Magdalénien III à dalles gravées mobiles (campagnes de fouilles 19371938). Bulletin de la Société préhistorique française 37(7-9). 149-154.

Quan, Hong. 2019. The representation and/or repression of Chinese women: From a socialist aesthetics to commodity fetish. Neohelicon 46(2): 717-737.

Samson, Alice V. M., Lucy J. Wrapson, Caroline R. Cartwright, Diana Sahy, Rebecca J. Stacey \& Jago Cooper. 2017. Artists before Columbus: A multi-method characterization of the materials and practices of Caribbean cave art. Journal of Archaeological Science 88. 2436.

Tolentino, Jia. 2019. The age of Instagram face: How social media, FaceTune, and plastic surgery created a single, cyborgian look. The New Yorker, December 12. https://www.newyorker.com/culture/decade-in-review/the-age-of-instagram-face (accessed 1 June 2020).

Yang, Saboya, Shuai Yang, Wenhan Yang \& Jiaying Liu. 2018. Automatic portrait oil painter: Joint domain stylization for portrait images. Multimedia Tools and Applications 77(13). 16113-16130.

Wei, Luo. 2012. Selling cosmetic surgery and beauty ideals: The female body in the web sites of Chinese hospitals. Women's Studies in Communication 35(1). 68-95. 


\section{Bionote}

\section{Massimo Leone}

Massimo Leone (b. 1975) is a full professor at the University of Turin, Italy, and a part-time professor at Shanghai University, China. His research interests include the semiotics of the face, the semiotics of digital cultures, visual semiotics, and the semiotics of religion. His publications include Religious conversion and identity: The semiotic analysis of texts (2004), Saints and signs: A semiotic reading of conversion in early modern Catholicism (2010), A cultural semiotics of religion (2018, in Chinese), and On insignificance (2019). 